\title{
REPRESENTAÇÃO, PARTICIPAÇÃO E COOPTAÇÃO NO CONSELHO MUNICIPAL DE MEIO AMBIENTE EM CAMPOS DOS GOYTACAZES/RJ
}

\author{
REPRESENTATION, PARTICIPATION AND CO-OPTING IN THE LOCAL \\ ENVIRONMENTAL COUNCIL IN CAMPOS DOS GOYTACAZES/RJ
}

Rodrigo Anido Lira ${ }^{1}$

Fabrício Barbosa Maciel $^{2}$

\section{RESUMO}

Em meados dos anos 1980, ocorreu uma reconfiguração do poder público no Brasil, destacando-se a autonomia dos municípios para gerir orçamentos e políticas públicas. Esse novo cenário possibilita melhor atendimento às demandas sociais e acompanhamento das ações e políticas públicas pela sociedade. Surgiram então algumas iniciativas, como a criação dos Conselhos Municipais. Como ponto positivo, identifica-se uma proposta de gestão democrática, para a sociedade ter um canal de participação e decisão, e como ponto crítico, a possibilidade do Conselho Municipal se transformar numa estrutura burocrática formal, com agentes cooptados pelo executivo municipal. Esse comprometimento da democracia local pode ainda ser potencializado em função dos volumosos recursos que certos municípios recebem em função das rendas do petróleo, como é o caso de Campos, escolhido como alvo desta pesquisa. Este trabalho pretende analisar os processos políticos locais com foco no Conselho Municipal de Meio Ambiente, visando identificar características da qualidade da participação e representação da sociedade nesse organismo e verificando a incidência de elementos que comprometam o processo democrático local, especialmente a ocorrência de formas de cooptação existentes. Os resultados da pesquisa apontaram problemas na participação, em função do elevado abstencionismo, e dificuldades em se fazer cumprir os regimentos e polarização dos debates.

Palavras-chave: Conselho Municipal de Meio Ambiente; Participação; Representação; Cooptação.

\begin{abstract}
In the mid 1980s, public power in Brazil was restructured, with an emphasis on the autonomy of towns to manage budgets and public policies. This new scenario enables better social services and monitoring of actions and policies by society. There then arose other initiatives such as the creation of Local Councils. On the positive side, these councils provide society with a democratic channel for participation and decision-making. The downside is that Local Councils can become formal bureaucratic structures, with agents co-opted by the municipal executive. This compromising of local democracy can also be caused by the considerable resources that some towns receive in oil revenues, as is the case of Campos, the focus of this study. The aim of the study is to analyze local political processes, focusing on the Local Environmental Council, to identify how society is represented and how it participates in the council, and the elements that compromise the local democratic process, especially co-opting. The results reveal problems in participation due to high rates of abstention and difficulties in complying with regulations and the polarization of debates.
\end{abstract}

Key words: Local Environmental Council; Participation; Representation; Co-opting.

Recebido 09/05/2013; Aceito 25/06/2013

\footnotetext{
${ }^{1}$ Doutor em Sociologia Política pela Universidade Estadual do Norte Fluminense (UENF). Professor da Universidade Candido Mendes/Campos-RJ. E-mail: rodrigoanidolira@gmail.com.

2 Doutor em Ciências Sociais pela Universidade Federal de Juiz de Fora (UFJF). Professor da Universidade Candido Mendes/Campos-RJ. E-mail: macielfabricio@gmail.com.
} 


\section{Introdução}

A Constituição de 1988 é o marco histórico para ser possível entender a nova dinâmica da gestão municipal. A descentralização ocorrida no modelo público pós-constituição transferiu o poder decisório para instâncias menores, especialmente os municípios, que enfrentam o desafio de gerir os próprios orçamentos e com autonomia para a criação de políticas públicas com alcance social, sintonizadas aos anseios sociais. Outro argumento favorável à descentralização é que a esfera de poder local permite maior atendimento às demandas sociais, além de possibilitar o acompanhamento das ações e políticas públicas por parte da sociedade, criando um ambiente propício ao exercício democrático.

Por outro lado, segundo Serra e Terra (2006), o aumento dos encargos sociais a cargo dos municípios e a recente tendência de recentralização de receitas exclusivas da união dificultam a sustentabilidade financeira dos municípios, também potencializados pela Lei de Responsabilidade Fiscal. Terra, Oliveira e Givisiez (2006) afirmam que a maior parte dos municípios, por não apresentar fontes de receitas próprias, depende quase que exclusivamente dos repasses dos Fundos de Participação dos Municípios (FPM).

Santos, Costa e Andrade (2001) ampliam essa questão afirmando que o critério de transferência de recursos dos fundos municipais privilegia os estados com maior número de municípios, não levando em conta os que realmente precisam de complementação financeira para as próprias receitas, equilibrando, dessa forma, o orçamento.

Fugindo à tendência da maioria dos municípios brasileiros encontram-se aqueles que se beneficiam de rendas compensatórias vindas da exploração de recursos naturais, como royalties e participações especiais, que potencializam a criação de políticas redistributivas e um ambiente democrático que possibilite investimentos mais igualitários na cidade. É o caso de Campos dos Goytacazes, que foi escolhida como alvo da pesquisa.

Dentro deste contexto, o tema acerca da gestão municipal e da democracia ganha novas dimensões quando se somam os recentes mecanismos de participação da sociedade organizada e os interesses que entram em conflito pelos recursos críticos, agora geridos pelos municípios. Em uma perspectiva normativa, os conselhos municipais se apresentam como uma das maiores mudanças institucionais da descentralização federativa, "cuja orientação central é a busca do aumento da participação direta da sociedade na gestão municipal e da eficiência e da efetividade das políticas públicas que vêm sendo descentralizadas desde a segunda metade dos anos 80". (SANTOS JUNIOR; RIBEIRO; AZEVEDO, 2004, p. 12).

Santos Junior, Ribeiro e Azevedo (2004) alertam para os riscos decorrentes deste processo, sendo o mais crítico a possibilidade de o conselho municipal se transformar numa estrutura burocrática formal, com agentes cooptados pelo executivo municipal.

Nesse contexto, pretende-se analisar neste artigo o Conselho Municipal de Meio Ambiente e Urbanismo do Município de Campos dos Goytacazes, visando identificar características da qualidade da participação e representação da sociedade nesses organismos e verificando a incidência de elementos que comprometam o processo democrático local, especialmente a ocorrência de formas de cooptação existentes no processo. 


\section{Canais democráticos de participação social}

Conforme aponta Nunes (1999), as experiências inovadoras, no Brasil, em termos de participação popular e de gestão voltada ao social, ocorreram na segunda metade dos anos 1970, ainda em plena ditadura militar. A partir da segunda metade da década de 1980, Lages, em Santa Catarina, Boa Esperança, no Espírito Santo, e Piracicaba, em São Paulo, são algumas das prefeituras que iriam inspirar um conjunto de experiências de política participativa que se desenvolveram no Brasil ao longo dos anos.

Os movimentos sociais representaram papel central em todo esse processo. As práticas participativas deles oriundas (os Conselhos Populares de Saúde da Zona Leste de São Paulo, a Assembleia do Povo, de Campinas, o Conselho Popular do Orçamento, de Osasco) também colaboraram para o arcabouço de ações que motivaram as gestões municipais a implementar políticas mais inclusivas.

Além disso, houve experiências internacionais que tiveram influência no Brasil, principalmente ligadas a gestões locais com governos de esquerda. É o caso das prefeituras italianas geridas por representantes do partido comunista italiano e, um pouco mais tarde, na Espanha, a experiência de Barcelona que, a partir de 1979, teve sucessivas gestões de esquerda (PSOE - Partido Socialista Obrero Español), com grande sucesso administrativo e social (BORJA apud LESBAUPIN, 2000).

O fator preponderante para o surgimento de tais práticas participativas foi a insurgência, nas décadas de 1970 e 1980, de "novos atores sociais que resgataram o termo sociedade civil e inauguraram, através de um amplo processo reivindicativo, novas formas de práticas políticas e formatos de sociabilidade, fundados em bases mais igualitárias" (GECD, 1999, p. 35).

Essa participação política, conforme relata Dias (2002), é o meio pelo qual o cidadão comum incorpora-se aos processos de formulação, decisão e implementação de políticas públicas, em outras palavras, a participação política é uma forma de o indivíduo influenciar decisões políticas tomadas por seus representantes. Essa influência pode ser medida desde a pressão política realizada por protestos da opinião pública, incluindo a mídia, até a incorporação de demandas populares por meio de canais institucionalizados entre o Estado e a Sociedade Civil.

Até o surgimento dessas inovações, as práticas políticas, historicamente no Brasil, se pautavam quase que exclusivamente por esquemas populistas, clientelistas e por mecanismos de cooptação política. O primeiro sinal de ruptura com esse modelo é a emergência dos Movimentos Sociais Urbanos (MSU), dos anos 1970. Segundo Scherer-Warren (1987), o desenvolvimento dos MSUs constituiu-se num marco de mudanças nas formas tradicionais de atuação das classes populares, havendo uma separação entre o tradicional e o novo.

Nesse cenário, o tradicional estaria, destacadamente, ligado às práticas políticas clientelistas das Sociedades Amigos de Bairros (SABs) do final da década de 1940. Já o novo modelo de atuação das classes populares caracteriza-se por meio de uma atuação política baseada: i) na autonomia diante do Estado e dos partidos políticos; ii) na negação e no combate às práticas clientelistas e às estratégias de cooptação política; iii) no enfrentamento direto com o poder público.

De acordo com Calderón (2008), os MSUs emergentes responsáveis por esse novo modelo organizavam-se em torno da verificação do cumprimento dos acordos firmados com o 
poder público, tendo como forma de pressionar os governantes as mobilizações públicas quando da não consecução de tais compromissos. Tornaram-se, assim,

germens de irradiação de uma nova cultura política-democrática que redefiniu as relações Estado-sociedade civil, concretizadas na atuação de uma série de administrações municipais estaduais e municipais progressistas que, ao longo da década de oitenta, esboçaram novos padrões de relacionamento com as classes populares (CALDERÓN, 2008).

Os novos padrões institucionais de relacionamento entre a sociedade organizada e o Estado possibilitaram o surgimento de novos canais de natureza poliárquica, nos quais se destacam: o Orçamento Participativo e a criação, a partir da Constituição de 1988, dos Conselhos Municipais.

Tais mecanismos possibilitaram não só aos movimentos sociais, mas também à sociedade organizada, uma forma de participação mais ampla, que alcançava, para além das negociações de bens públicos, as formulações de diretrizes para determinadas políticas públicas, bem como a interferência direta na alocação dos recursos municipais.

Em um país onde tradicionalmente se observa a hierarquização das relações sociais e a apropriação do público pelo privado, a criação desses espaços institucionalizados de interação revela-se fundamental para o fortalecimento da qualidade democrática e para a construção de novos parâmetros que possibilitassem a concepção de uma mudança na gramática política de até então.

A Constituição de 1988 é o marco histórico-político para se entender a nova dinâmica da gestão municipal. A descentralização ocorrida no modelo federativo pós-constituição transferiu parte do poder decisório para instâncias menores, especialmente os municípios, que, agora autônomos, enfrentavam o desafio de gerir, com seus próprios orçamentos (lato sensu), políticas públicas setorizadas advindas das novas competências constitucionais.

Ressalte-se que o conceito de descentralização utilizado neste trabalho segue o entendimento de Marta Arretche (1996, p. 16):

“Descentralização" aqui significa genericamente a
"institucionalização no plano local de condições técnicas para a
implementação de tarefas de gestão de políticas sociais". Assim, é
indiferente se a descentralização da política sob análise toma a forma
da estadualização e/ou da municipalização. A noção "local” estará, na
verdade, referida à unidade de governo para a qual se pretende
transferir atribuições.

A descentralização como transferência de competências referente ao pacto federativo, instituído pelo artigo 18 da Constituição Federal de 1988, encontra na autonomia dos entes federados a discricionariedade necessária à atuação de suas novas atribuições. 
Essa autonomia assume quatro contornos essenciais: $i$ ) autonomia política - eleição direta para os cargos dos Poderes Executivo e Legislativo; auto-organização por meio da elaboração da própria lei de organização político-administrativa; impossibilidade de intervenção de outras esferas de governos, salvo em casos previstos na Constituição Federal; ii) autonomia administrativa - capacidade de organizar suas atividades, criar seus quadros de servidores, gerir e prestar os serviços de sua competência; iii) autonomia financeira capacidade de gerir e arrecadar seus próprios tributos; $i v$ ) autonomia legislativa - capacidade de legislar sobre os assuntos de sua competência, seja ela privativa, exclusiva ou concorrente.

Os conselhos municipais, por poderem atuar em certos setores de ação governamental, como saúde, educação, direitos da criança e do adolescente, patrimônio cultural, entre outros, com o poder para formular propostas de programas e políticas públicas, assim como para fiscalizar o setor ao qual está envolvido (CUNHA, 1997, p. 96), acabam se tornando, em certa medida, uma das referências:

ao aperfeiçoamento e ao aprofundamento das instituições democráticas, com vistas a permitir sua operação nos interstícios eleitorais, acoplando aos mecanismos clássicos da representação formas institucionalizadas de participação política, que permitam a ampliação do direito de vocalização das preferências dos cidadãos e o controle público do exercício do poder (AZEVEDO; ANASTASIA, 2000, p. 3).

Dentre as características observadas nos conselhos e que são importantes para o atendimento das expectativas sobre tais órgãos, pode-se citar "a sua função deliberativa ou consultiva, sua composição interna e seu grau de flexibilidade para incorporar novas representações coletivas" (CUNHA, 1997, p. 96). Esses atributos sugerem maiores ou menores chances de êxito para a resposta ao desafio da democracia. Sob essa perspectiva, a participação e a representação são as variáveis em torno das quais as demais questões gravitam.

Conceitualmente, os conselhos municipais são órgãos públicos do Poder Executivo local (GOHN, 2001; AVRITZER, 2006). Segundo Di Pietro (2004, p. 428), órgão público é "uma unidade que congrega atribuições exercidas pelos agentes públicos que o integram com o objetivo de expressar a vontade do Estado". Por conseguinte, os conselhos municipais, no que tange ao resultado de suas deliberações, fazem com que as vontades, os interesses agregados ou consensualizados dos participantes, inseridos na arena de discussão, passem a ser a vontade do próprio Estado.

Desse modo, se os conselhos gestores são órgãos públicos, estes são, como conceitua Bucci (2002, p. 329), "órgãos públicos de natureza sui generis", uma vez que, apesar de as atividades dos conselhos darem-se em um contexto sociopolítico de descentralização, eles acabam inseridos em outro processo, o de desconcentração, por meio do qual há a distribuição de competências dentro de uma mesma pessoa jurídica, organizada hierarquicamente. "As atribuições administrativas são outorgadas aos vários órgãos que compõem a hierarquia, criando-se uma relação de coordenação e subordinação entre uns e outros" (DI PIETRO, 2004, p. 349). 
Ainda assim, Santos Junior, Ribeiro e Azevedo (2004) alertam para os riscos decorrentes desse processo, sendo o mais crítico a possibilidade de o conselho municipal se transformar numa estrutura burocrática formal, com agentes cooptados pelo executivo municipal.

Esse cenário sinaliza que a simples existência dos conselhos não garante sua eficácia. A promoção da experiência de participação e de gestão democrática das políticas públicas no âmbito local não é consequência natural da implantação dos conselhos. É fundamental que se perceba com clareza as dificuldades para a consolidação de espaços públicos verdadeiramente participativos.

Essas dificuldades se justificam, nas palavras de Teixeira (1999), em relação ao novo cenário democrático, pois "o coronelismo acaba se adaptando às novas estruturas gerenciais e às novas exigências democráticas, prevalecendo firme, sobrevivendo aos novos tempos políticos". Ao longo do tempo, as práticas políticas participativas na vida pública assumiram diversas matizes no processo de interlocução Estado-sociedade organizada, a partir dos comportamentos políticos que também oscilavam entre processos de cooptação e representação democrática.

\section{O Conselho Municipal de Meio Ambiente e Urbanismo em Campos dos Goytacazes}

A pesquisa no Conselho Municipal de Meio Ambiente e Urbanismo de Campos dos Goytacazes ocorreu de novembro de 2010 a setembro de 2011. Um extenso período de tempo em função das dificuldades na localização e interface com os conselheiros. No intuito de se atingir os objetivos do trabalho, foram realizadas pesquisas das seguintes naturezas:

- Documental: A pesquisa consistiu no levantamento e análise de documentos diversos referentes ao Conselho, tais como: leis, estatutos, regimentos, atas de reunião. Esse material foi colhido na Secretaria Municipal de Meio Ambiente;

- Qualitativa: Entrevistas semiestruturadas com seis conselheiros, dois quais três eram ligados ao Executivo municipal e três à sociedade civil, visando principalmente identificar a ocorrência e formas de cooptação na gestão dos Conselhos;

- Observação participante: Participação como ouvinte em reuniões, a fim de estabelecer como se dividiam os Conselhos em termos de grupos de interesses, assim como perceber a dinâmica dos debates e as deliberações.

O Conselho Municipal de Meio Ambiente e Urbanismo (CMMAU), do município de Campos dos Goytacazes, foi criado no ano de 1994, logo após a criação da Secretaria Municipal de Meio Ambiente, no governo do prefeito Sérgio Mendes (1993-1996). O surgimento do CMMAU seguiu uma tendência pós-constituição de 1988, que concedeu autonomia aos municípios para desenvolverem políticas de âmbito local, contemplando a criação de conselhos municipais que participassem de maneira consultiva e/ou deliberativa das decisões do executivo municipal.

No plano diretor do Município, elaborado em 2006 (e publicado em 2008), o CMMAU tem participação protagonista com o maior número de citações, sendo responsável por inúmeras atribuições relacionadas a consultas e deliberações sobre questões do ambiente de maneira geral. Ao longo de sua história, apresentou alguns percalços que valem menção 
por denotar em linhas gerais um senso democrático distorcido das autoridades municipais com o artifício da cooptação presente em sua trajetória.

De acordo com os relatos das entrevistas, no ano seguinte ao da criação do conselho, o prefeito Sergio Mendes exonera os conselheiros do CMMAU e nomeia outros mais favoráveis a uma causa específica: a construção de um posto de gasolina numa área entendida como de risco pelo conselho, que vetou a construção. A explicação para essa atitude política foi que o empresário interessado na empreitada possuía laços familiares com o então prefeito. $\mathrm{O}$ Ministério Público (MP) precisou ser acionado para intervir na situação e garantir a decisão do CMMAU. Antes da decisão final do MP, segundo relatos das entrevistas, foram inúmeras as tentativas de cooptação dos conselheiros para que se sensibilizassem com a causa privada.

Após esse impacto inicial, o conselho praticamente não funcionou por desinteresse do executivo municipal. Somente em 2004, quando ocorre novamente uma mudança política na prefeitura, o recém nomeado Secretário Municipal do Meio ambiente, mais sensível às causas de sua pasta, reestrutura o CMMAU e retoma as reuniões sistemáticas, apesar das dificuldades na obtenção de quórum e da presença de entidades pouco representativas ou de natureza estranha aos temas discutidos no conselho.

\subsection{A estrutura do conselho}

A estrutura do CMMAU é paritária, composta de 28 instituições, comportando 14 representantes de organizações governamentais (municipais, estaduais e federais) e seus respectivos suplentes e 14 representantes de organizações não governamentais e seus respectivos suplentes. As reuniões ordinárias ocorrem mensalmente, sempre nas primeiras quartas-feiras de cada mês. Por questões regimentares, as reuniões somente ocorrem com a presença da maioria absoluta dos conselheiros. Neste quesito, ressalta-se que as ausências sem justificativa em cinco reuniões anuais ou três seguidas acarretam para a referida instituição a perda da vaga no conselho. Porém, nas palavras do Secretário Executivo do conselho, se esse critério fosse seguido à risca, seria difícil manter o conselho ativo, pois grande parte das instituições ultrapassa o mínimo permitido de faltas. Só em 2010 foram contabilizadas, das doze previstas, seis reuniões ordinárias canceladas por falta de quórum.

O presidente do conselho normalmente é o secretário da pasta e é indicado/nomeado pelo prefeito, já o vice é escolhido pelas organizações não governamentais integrantes do conselho. Cabe ao presidente indicar o secretário executivo, convocar e presidir as reuniões, dirigir a entidade, representá-la em juízo ou fora dele e participar das votações. Ao vicepresidente compete substituir o presidente em suas ausências e participar das votações. Nesse caso, na gestão atual é constante a substituição do presidente nas reuniões, pois ele justifica as ausências por possuir compromissos profissionais privados que existiam anteriormente às suas funções como secretário e presidente do CMMAU.

Ao secretário executivo cabe a elaboração das atas de reuniões, bem como toda correspondência, relatórios anuais e outros documentos, assinando-os em conjunto com o presidente. Além de servir como elemento de interlocução entre as instituições participantes do conselho com outros órgãos da união, estado e municípios, mantendo-se atualizado sobre as questões ligadas ao meio ambiente e urbanismo, e não terá direito a voto nas plenárias. Percebe-se um esforço do secretário executivo em cumprir suas funções, mas nota-se que, por ser funcionário nomeado (não concursado), não estável em sua atividade, portanto mais 
dependente do executivo municipal, atua com excesso de zelo e comedimento na interface do conselho com a Secretaria de Meio Ambiente.

O Regimento contempla ainda a criação de câmaras técnicas, caso se faça necessário a discussão específica sobre algum tema de caráter consultivo, sendo que as deliberações ocorrem exclusivamente nas plenárias.

\subsection{Configuração e dinâmica de atuação}

Durante o período da pesquisa, foram analisadas três reuniões ordinárias, uma extraordinária (participação como ouvinte) e outras três reuniões ordinárias (participação como conselheiros titulares, representando a Universidade Candido Mendes). As observações que surgiram dessas participações foram importantes para as percepções sobre a dinâmica do conselho, identificação de grupos de interesse e posicionamento dos conselheiros quanto ao papel desempenhado no CMMAU. Além das observações, foram realizadas seis entrevistas com conselheiros, sendo três deles representantes do Executivo Municipal e três representantes da sociedade civil.

No tocante à cooptação, percebem-se algumas variáveis que influenciam o processo. $\mathrm{O}$ fato de um conselheiro ser representante da prefeitura o torna mais exposto à cooptação, e a exposição é ainda maior se este não for concursado, o que não lhe garante estabilidade no cargo. As instituições da sociedade civil de caráter privado que prestam ou possuem interesse em prestar algum tipo de serviço para a prefeitura também possuem potencial significativo de cooptação, ao passo que as instituições públicas das esferas federais e estaduais, dependendo do alinhamento político de suas organizações, podem apresentar baixo potencial de cooptação.

QUADRO 1 - Potencial de cooptação

\begin{tabular}{|l|l|}
\hline $\begin{array}{l}\text { Nível/potencial de } \\
\text { cooptação }\end{array}$ & Perfil do conselheiro \\
\hline Alto & $\begin{array}{l}\text { Funcionário da prefeitura não concursado; Representante de } \\
\text { Instituições com alinhamento político com a prefeitura. }\end{array}$ \\
\hline Médio & $\begin{array}{l}\text { Funcionário da prefeitura concursado; Representante de } \\
\text { Instituições que desenvolvem projetos financiados pela } \\
\text { prefeitura. }\end{array}$ \\
\hline Baixo & $\begin{array}{l}\text { Representante de instituições privadas e públicas não } \\
\text { dependentes da prefeitura. }\end{array}$ \\
\hline
\end{tabular}

Fonte: Lira (2012).

No tocante ao potencial de cooptação, seguindo os critérios definidos no Quadro 1, o CMMAU se encontra dividido da seguinte forma: cinco conselheiros com alto potencial de cooptação, oito com médio potencial e oito com baixo potencial. Os números demonstram que apenas $38 \%$ dos conselheiros apresentam baixo potencial de cooptação, sem contar os possíveis desvios de instituições, que possuem perfil de baixa cooptação mas, ainda assim, 
podem estar cooptadas, como no caso já citado da reconhecida entidade de classe. Esse cenário reforça a fragilidade da instituição relativa à possibilidade de cooptação de seus membros.

As reuniões ordinárias do CMMAU estão marcadas pelo regimento interno para as primeiras quartas-feiras de cada mês. A primeira chamada começa às $18 \mathrm{~h} 30$. No caso de não haver número mínimo suficiente de conselheiros para o início da reunião, aguarda-se mais 30 minutos para a segunda chamada. Em nenhuma das sete reuniões analisadas, o início ocorreu na primeira chamada, ficando evidente em todos os momentos a preocupação com a não ocorrência da reunião por falta de quórum, uma situação historicamente recorrente nesse conselho.

Em nenhuma das reuniões observadas houve participação do presidente do conselho, em todos os casos, foi preciso a participação do vice-presidente. O próprio Secretário Executivo, que é funcionário nomeado da Secretaria de Meio Ambiente de Campos, por vezes tentou justificar a ausência do presidente, que é o Secretário de Meio Ambiente, portanto seu chefe na prefeitura, com alguns argumentos. Conforme suas palavras: "Ele dá aulas numa faculdade nos dias das reuniões do CMMAU, por isso não pôde vir. Está certo, pois ele não pode abrir mão de um trabalho que já tinha antes de assumir este cargo". Na entrevista com o secretário, a questão foi retomada e, ao ter de responder por que não participa das reuniões, foi enfático: "Hoje eu estou secretário de meio ambiente, mas não sei o dia de amanhã, não posso sair do meu emprego privado".

Em outros conselhos municipais de Campos, percebe-se que o esvaziamento das reuniões é ainda mais grave. No caso, o CMMAU ainda apresenta alguma regularidade nos encontros e potencial de mobilização, que pode ser atribuído ao fator ideológico ligado a questões ambientais, que possuem forte apelo entre correntes da sociedade.

Esses segmentos sociais específicos, dotados de maior capital social (PUTNAM, 1996), conseguem melhor capacidade de mobilização, que faz com que o conselho perdure mesmo em função das variáveis contrárias.

A dificuldade na obtenção mínima de representações para o início das reuniões é regularmente discutida nas plenárias. A sugestão que ganha cada vez mais adeptos é a diminuição do número de representantes, para que seja possível, com menor quórum, viabilizar as reuniões. Esse ajuste serviria também para selecionar de maneira mais criteriosa as entidades, priorizando a vocação para as questões ambientais.

Nesse contexto, vale ressaltar, mais uma vez citando Nunes e Anastásia (2006), uma preocupação quanto às maneiras de se estabelecer as entidades como partes integrantes dos conselhos. Para os autores, "quanto mais consensual e democrática for a representatividade, menos distorções ocorrerão na representação política" .

A representatividade é uma garantia de que as decisões coletivizadas no conselho serão legitimadas, caso contrário, os setores prejudicados buscarão alternativas para a consecução de seus objetivos. Esse enxugamento do conselho pode representar um comprometimento da representação, ainda que com o argumento do aumento da efetividade dos processos (agilidade e objetividade das discussões nas reuniões e facilidade para obtenção de quórum).

O importante nestes casos é perceber que a melhor forma de escolha será aquela que promova mais eficazmente um elenco de entidades dos setores da sociedade ligados ao tema do conselho que proporcionem a maior representação possível. Em última instância, numa visão democrática, não caberia aos próprios conselheiros deliberarem pela diminuição das 
representações no conselho, mas promoverem uma discussão mais ampla na sociedade sobre a questão.

Além da Constante falta de quórum, outros problemas impactam no funcionamento do CMMAU. As pautas das reuniões costumam ser criticadas por invariavelmente não conterem assuntos mais objetivos e relevantes que possam surtir efeito na sociedade. Em uma das reuniões, por exemplo, as discussões sobre a implementação do código ambiental durou três horas para a revisão de 7 dos 257 artigos do código. Levou-se uma hora somente para a discussão da terminologia a ser utilizada: ambiente ou meio ambiente. Cenários como esse também são apontados como elementos que desestimulam a participação.

Outra situação recorrente percebida nas observações e entrevistas é a polarização dos debates, normalmente centrada em dois ambientalistas. Esse fato ocorre não por omissão das demais representações, mas pelo teor técnico de muitas discussões, que fogem ao conhecimento de muitos conselheiros, reativando a tese da presença de instituições de natureza estranha à temática do conselho, tornando-as alheias ao debate e desinteressando-as. Este panorama reforça a tese de Schumpeter (1961), que sugere que o cidadão está excluído do processo democrático, cuja dinâmica é ditada exclusivamente pela disputa entre elites. Assim, a democracia constitui apenas um conjunto de regras, procedimentos, instituições e condições dessa competição.

Outra dificuldade apontada se relaciona ao local escolhido para as reuniões, que ocorrem na própria Secretaria de Meio Ambiente, situada em um dos andares do prédio de uma empresa de capital privado, que fica em um bairro relativamente afastado do centro da cidade, com certas limitações de aceso por transportes coletivos. Para um dos conselheiros entrevistados:

A mudança de local das reuniões dificultou o acesso e a possibilidade de participação da sociedade. As reuniões ocorrem numa empresa privada que abriga a SMMA, além de ser longe do centro, para entrar lá precisamos de identificação e passar por uma cancela.

Nesse contexto, percebem-se as dificuldades democráticas locais. A falta de interesse do Executivo Municipal em gerar uma política mais participativa é perceptível pela falta de visibilidade do conselho, estrutura física inadequada, morosidade de retorno de deliberações e desinteresse da Secretaria de Meio ambiente, questões que acabam potencializando o desestímulo dos conselheiros e criando barreiras a uma participação social mais ampla.

\section{Conclusão}

Após a promulgação da Constituição da República Federativa do Brasil, em 1988, novos arranjos institucionais se fizerem presentes no federalismo brasileiro. Além da União, dos estados-membros e do Distrito Federal, os municípios foram elevados ao status de entes federativos, com todas as autonomias atribuídas a estes pela Constituição.

Nesse contexto, a discussão da democracia no âmbito local ganha nova dimensão, com o surgimento de alguns canais decisórios participativos, com destaque para os conselhos 
municipais que atuam em certos setores de ação governamental, como saúde, educação, meio ambiente e patrimônio, por exemplo, tendo poder para formular propostas de políticas e programas, assim como para fiscalizar o setor com o qual está envolvido.

Contudo, a promoção da experiência de participação e de gestão democrática das políticas públicas no âmbito local não é consequência natural da implantação dos conselhos, ou seja, apesar de se constituir em um avanço no tocante à democracia, a simples existência dos conselhos municipais não garante sua eficácia. Assim, é fundamental que se perceba com clareza as dificuldades para a consolidação de espaços públicos verdadeiramente participativos. O risco mais crítico decorrente desse processo é a possibilidade de o conselho municipal se transformar numa estrutura burocrática formal, com agentes cooptados pelo executivo municipal.

Algumas variáveis podem influenciar esse risco, como as formas de implantação e constituição dessas entidades, que em alguns casos pode ocorrer por pressão do Ministério Público e/ou juizados especiais, e em outros, pela própria sociedade civil organizada, porém, na maioria dos casos, trata-se de um engajamento instrumental, orquestrado pelo executivo municipal com foco no recebimento de recursos públicos.

O Conselho Municipal de Meio Ambiente e Urbanismo em Campos foge a esta "regra", pois não recebe verbas públicas, mas trata-se de uma área estratégica para o município, pois em sua esfera de atuação estão questões ligadas, por exemplo, ao planejamento urbano da cidade, o que pode interferir em iniciativas do próprio município e no interesse de grandes empresas construtoras que invariavelmente aparecem na relação dos maiores financiadores privados das campanhas eleitorais locais.

Com esse argumento, percebe-se que a existência e permanência do CMMAU no cenário local tem como base o interesse do município em manter uma entidade que respalde suas ações e iniciativas políticas, comumente questionadas pelo Ministério Público e/ou Tribunal de Contas. A certeza do endosso das ações públicas por parte do conselho se dá em função da fragilidade da estrutura desse órgão, cuja maioria dos conselheiros, como visto na pesquisa, tem potencial significativo de cooptação. Em alguns casos, os que apresentam baixo potencial de cooptação estão alheios aos debates mais técnicos por desconhecimento da área temática do conselho.

Essa capacidade de articulação e poder do município no âmbito do conselho é evidenciada por um caso que retrata uma das poucas vezes em que a atuação do CMMAU pareceu ser eficiente (porém, não isenta), relacionado à construção de uma ponte no centro da cidade, que ficou conhecida como ponte "Rosinha". O conselho se posicionou contra a construção do empreendimento de iniciativa do governo do estado alegando localização inapropriada. A governadora na ocasião era a atual prefeita do município, Rosinha Garotinho (que deu nome à ponte) e o prefeito municipal do período do impasse era um desafeto político, Arnaldo Vianna. A articulação do governo municipal com o Conselho de Meio Ambiente conseguiu paralisar as obras por alguns meses, até que o governo estadual ganhasse na justiça a autorização para continuar o trabalho.

Esse exemplo denota claramente que o conselho possui potencial de funcionamento alinhado à sua finalidade original, mas que depende das "intenções democráticas" e interesses do Executivo Municipal, responsável por coordenar os mecanismos decisórios participativos locais, além de ter poder para interferir por meio da cooptação, impactando diretamente no conjunto de liberdades que asseguram o exercício dos direitos de cidadania, comprometendo o processo democrático. No município, a força política do governo é proporcional à sua 
capacidade de cooptação, então, quanto maior a cooptação, mais recursos para manter o controle de suas bases.

O único caso registrado no conselho em que não houve um posicionamento alinhado aos interesses do executivo municipal foi referente a um veto do CMMAU a um pedido da prefeitura para a liberação de um terreno localizado em área considerada de risco para a construção de um posto de gasolina. A explicação para essa atitude política foi que o empresário interessado na empreitada possuía laços familiares com o então prefeito. Ao longo do processo, foram inúmeras as tentativas de cooptação dos conselheiros para que se sensibilizassem com a causa privada. Desta forma, o Ministério Público (MP) precisou ser acionado para intervir na situação e garantir a decisão do conselho municipal.

O caso acabou virando emblemático. Apesar de ser praticamente o único bom exemplo em termos de eficiência e isenção política, percebeu-se pelo depoimento de alguns entrevistados que faziam parte do CMMAU na época que a "vitória" do conselho contra o município ocorreu mais pela subestimação da prefeitura com relação ao poder deste novo órgão, já que o evento ocorreu nos anos 1990, período de surgimento dos conselhos municipais, do que por méritos do sistema participativo em si. Segundo as palavras de um dos entrevistados: "Os conselheiros na época da questão do terreno do posto não estavam devidamente cooptados pela prefeitura".

\section{REFERÊNCIAS}

ARRETCHE, Marta T. S. Mitos da descentralização: mais democracia e eficiência nas políticas públicas. Revista Brasileira de Ciências Sociais, São Paulo, n. 31, ano 11, jun. 1996.

AVRITZER, Leonardo. Reforma política e participação no Brasil. Belo Horizonte: Editora da UFMG, 2006.

AZEVEDO, Sérgio; ANASTASIA, Fátima. Governança, accountability e responsividade: reflexões sobre a institucionalização da participação popular em experiências desenvolvidas e Minas Gerais. In: ENCONTRO DA ASSOCIAÇÃO BRASILEIRA DE CIÊNCIA POLÍTICA, 2., 2000, São Paulo. Anais... São Paulo: PUC, 2000.

BUCCI, Maria Paula Dallari. Gestão democrática da cidade. In: DALLARI, Adilson Abreu; FERRAZ, Sérgio (Org.). Estatuto da Cidade. São Paulo: Malheiros, 2002. p. 322-341.

CALDERÓN, Adolfo Ignácio. Conselhos Municipais: representação, cooptação e modernização da política patrimonialista. In: SOUZA, Donaldo Bello de (Org.). Conselhos Municipais e Controle Social da Educação. São Paulo: Xamã, 2008.

CUNHA, Flávio Saliba. Patrimônio cultural e gestão democrática em Belo Horizonte. Varia História, Belo Horizonte, n. 18, p. 83-100, set. 1997.

DI PIETRO, Maria Sylvia Zanella. Direito Administrativo. 15. ed. São Paulo: Atlas, 2004. 
DIAS, Marcia Ribeiro. Sob o signo da vontade popular: o orçamento participativo e o dilema da Câmara Municipal de Porto Alegre. Belo Horizonte: Editora UFMG; Rio de Janeiro: IUPERJ. 2002.

GECD - GRUPO DE ESTUDOS SOBRE A CONSTRUÇÃO DEMOCRÁTICA. Os movimentos Sociais e a Construção Democrática: Sociedade Civil, Esfera Pública e Gestão Participativa. Idéias - Revista do Instituto de Filosofia e Ciências Humanas, Universidade de Campinas, v. 5, n. 2, 1999.

GOHN, Maria da Glória. Papel dos conselhos gestores na gestão pública. São Paulo: Informativo CEPAM, ano I, n. 3, p. 7-17, 2001.

LESBAUPIN, Ivo. Poder Local $\mathbf{x}$ Exclusão Social: a experiência das prefeituras democráticas no Brasil. Rio de Janeiro: Vozes, 2000.

LIRA, Rodrigo Anido. Representação, Participação e Cooptação nos Conselhos Municipais em Campos dos Goytacazes. 2012. Tese (Doutorado em Sociologia Política) Universidade Estadual do Norte Fluminense Darcy Ribeiro, Rio de Janeiro, 2012.

NUNES, Edson. A gramática política do Brasil: clientelismo e insulamento burocrático. Rio de Janeiro: Zahar, 1999.

NUNES, Felipe; ANASTASIA, Fátima. A reforma da representação. In: ANASTASIA, Fátima; AVRITZER, Leonardo (Org.). Reforma política no Brasil. Belo Horizonte: Editora da UFMG, 2006. p. 17-33.

PUTNAM, Robert David. Comunidade e democracia: a experiência da Itália moderna. Rio de Janeiro: Fundação Getulio Vargas, 1996.

SANTOS, Angela Moulin Simões Penalva; COSTA, Laís Silveira; ANDRADE, Thompson Almeida. Federalismo no Brasil: análise da descentralização financeira da perspectiva das cidades médias. In: ANDRADE, Thompson Almeida; SERRA, Rodrigo Valente. Cidades médias brasileiras. Rio de Janeiro: IPEA, 2001. p. 295-335. Disponível em: <http://nemesis.org.br/sec-din5.php?id=0000000064\&i=en>. Acesso em: 29 jul. 2013.

SANTOS JUNIOR, Orlando Alves; RIBEIRO, Luiz Cesar de Queiroz; AZEVEDO, Sérgio de. Democracia e gestão local: a experiência dos conselhos municipais no Brasil. In: SANTOS JUNIOR, Orlando Alves; RIBEIRO, Luiz Cesar de Queiroz; AZEVEDO, Sérgio de. (Org.). Governança democrática e poder local: a experiência dos conselhos municipais no Brasil. Rio de Janeiro: Revan, 2004.

SCHERER-WARREN, Ilse. O caráter dos novos movimentos sociais. In: SCHERERWARREN, Ilse; KRISCHKE, Paulo J. (Org.). Uma revolução no cotidiano? Os novos movimentos sociais na América Latina. São Paulo: Brasiliense, 1987. 
SCHUMPETER, Joseph A. Capitalismo, socialismo e democracia. Rio de Janeiro: Fundo de Cultura, 1961.

SERRA, Rodrigo Valente; TERRA, Denise Tavares. Notas sobre a região petro-rentista da Bacia de Campos. In: CARVALHO, Ailton Mota de; TOTTI, Maria Eugenia Ferreira. Formação Histórica e Econômica do Norte Fluminense. Rio de Janeiro: Garamond, 2006. p. 275-307.

TEIXEIRA, Marco Antônio Carvalho. Voto e clientelismo na cidade de São Paulo. 1999. Dissertação (Mestrado em Políticas Sociais) - Pontifícia Universidade Católica de São Paulo, São Paulo, 1999.

TERRA, Denise Cunha; OLIVEIRA, Elzira Lúcia de; GIVISIEZ, Gustavo Henrique. Os Municípios novos ricos do petróleo são mais solidários com sua população? In: COLÓQUIO INTERNACIONAL SOBRE O PODER LOCAL, 10., 2006, Salvador. Anais... Salvador, 2006. Disponível em: <http://www.royaltiesdopetroleo.ucam-campos.br/?cod=4>. Acesso em: 29 jul. 2013. 